\title{
Detection of the damage caused to DNA by a thiophene- $S$-oxide using an electrochemical DNA-biosensor
}

\author{
Ana Maria Oliveira Brett ${ }^{\mathrm{a}, *}$, Luis Antônio da Silva ${ }^{\mathrm{a}}$, Hideki Fujii ${ }^{\mathrm{b}}$, \\ Shuntaro Mataka ${ }^{c}$, Thies Thiemann ${ }^{c}$

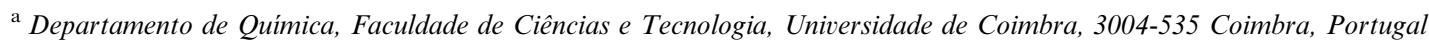 \\ ${ }^{\mathrm{b}}$ Interdisciplinary Graduate School of Engineering, Kyushu University, 6-1, Kasuga-koh-en, Kasuga-shi, Fukuoka 816-8580, Japan \\ ${ }^{\mathrm{c}}$ Institute of Advanced Material Study, Kyushu University, 6-1, Kasuga-koh-en, Kasuga-shi, Fukuoka 816-8580, Japan
}

Received 12 November 2002; accepted 19 March 2003

\begin{abstract}
The electrochemistry of 3,4-dibenzyl-2,5-dimethylthiophene- $S$-oxide was investigated as well as its interaction with dsDNA. The electrochemical study of the thiophene- $S$-oxide was performed at different $\mathrm{pH}$ values, in a mixed solvent and by solid state voltammetry, and showed that the molecule is reduced at a very negative potential, and the reduction is $\mathrm{pH}$ dependent. A glassy carbon electrode modified with a thick thiophene- $S$-oxide + dsDNA mixture was used to study the interaction of thiophene- $S$-oxide in situ with dsDNA at a charged interface. The experimental results give strong evidence that the reduced thiophene- $S$-oxide interacts with dsDNA causing damage with possible strand break and that the thiophene-S-oxide adduct formed with dsDNA can still undergo reduction.
\end{abstract}

(C) 2003 Elsevier Science B.V. All rights reserved.

Keywords: Thiophene-S-oxide; DNA-biosensor; Oxidative damage; 8-Oxoguanine; Voltammetry; Electrochemistry; Oxidation; Reduction; DNAelectrochemical biosensors

\section{Introduction}

Thiophene- $S$-oxides are a new group of compounds with very interesting properties, only recently isolated and characterised in their pure form [1].

Thiophene- $S$-oxides show different reduction behaviour in the presence and absence of proton donors. In the absence of proton donors, the reduction potential of the compounds is dependent on the substituents of the molecules. In the presence of proton donors, the substituents play a less significant role and a number of thiophene- $S$-oxides were reduced electrochemically to the corresponding thiophene in the presence of a tenfold excess of benzoic acid in acetonitrile solution [2]. Another electrochemical study with similar compounds [3] also using a non-aqueous solvent, acetonitrile, and

* Corresponding author. Tel./fax: +351-239-835-295.

E-mail address: brett@ci.uc.pt (A.M.O. Brett). very negative reduction potentials, not possible to reach in aqueous solutions, was carried out.

Theoretical calculations and electrochemical data showed that the functionalization of thiophene to the corresponding $S$-oxide produces a dramatic increase in the electron affinity and affects the reduction potential to a greater extent than the oxidation potential [4]. Theoretical ab initio calculations indicated a non-planar structure for thiophene- $S$-oxides with the sulphur atom lying outside the plane formed by the other four atoms by $0.26 \AA$, which in the meantime has been proven by $\mathrm{X}$-ray crystal structural analysis [5].

The biological activity of some thiophene- $S$-oxides against a number of cancer cells [6] might be attributable to a slight but continued deoxygenation of the compounds. Typically, the thiophene- $S$-oxides were tested in a 3-cell line, one dose primary anti-cancer assay. 2,5dimethyl-3,4-dibenzylthiophene- $S$-oxide showed, at a concentration of $10^{-4} \mathrm{M}$, an effect on the growth of CND cancer cells SF-268 of $-83 \%$. Subsequently, the 
compound was also tested in a full panel of 60 tumour cell lines [6].

There has also been a study showing that thiophene$S$-oxides can be metabolic intermediates of dietary thiophenes in rats [7]. Direct evidence for the involvement of thiophene- $S$-oxide as the key primary reactive intermediate in the metabolism of thiophene in vivo was obtained from the detection of dihydrothiophene sulfoxide mercapturate excreted in rat urine, which derived from the reaction of glutathione with the very reactive thiophene sulfoxide [8]. The other fate described for thiophene- $S$-oxide in vivo is its dimerization via a Diels-Alder reaction [9]. The structure of these thiophene- $S$-oxide dimers was established and the formation of thiophene- $S$-oxide dimers in the metabolism of thiophene in vivo in rats and in vitro by rat liver microsomes reported [9].

The potential anti-cancer activity of the thiophene- $S$ oxides has instigated a study of the use of estradiol derivatives as carriers of thiophene- $S$-oxides to breast cancer cells [6]. Since the receptor for these carriers resides inside the cell nucleus, it seemed appropriate to assess initially the effect of thiophene- $S$-oxides on DNA material.

The need for the analysis of gene sequences, oxidative damage to DNA and the understanding of DNA interactions with molecules or ions led to the development of DNA-based biosensors [10-13]. The DNAelectrochemical biosensor is a device that incorporates immobilised DNA as the molecular recognition element in the biologically active layer on the electrode surface, and measures specific binding processes with DNA using an electrochemical transducer. The electrochemical behaviour, adsorption of DNA and electrochemical oxidation of dsDNA, and synthetic nucleic acids has been studied on carbon electrodes and showed that all bases-guanine $(\mathrm{G})$, adenine (A), cytosine (C) and thymine $(\mathrm{T})$ - can be oxidised, the oxidation reaction involving two electrons and two protons which means that the oxidation potential values vary with the supporting electrolyte $\mathrm{pH}$ in a $\mathrm{pH}$ dependent mechanism [14-17]. The occurrence of oxidative damage to dsDNA by hazardous compounds leads to the breaking of the hydrogen bonds and opening of the double helix. This causes the bases to come into contact with the electrode surface and enables electrochemical detection of the oxidative damage by monitoring the oxidation of the bases.

The electrochemical DNA-biosensor has been used to sense in situ oxidative damage to DNA. The electrochemical data can contribute to the elucidation of the mechanism by which DNA is oxidatively damaged by some compounds with a view to what occurs in the living cell $[18,7-10]$. Interactions of several substances with dsDNA have been successfully studied using the DNA-electrochemical biosensor [11-13,16], and allow clarification of the interaction with dsDNA as well as its electrochemical mechanism.

Some compounds can promote oxidative damage to DNA in cancerous cells through the generation of reactive oxygen species [19,20] and high levels of 8-oxoguanine (8-oxoG), a known biomarker of oxidative stress, were detected in in vitro studies [21]. The generation of this main product of guanine oxidation within DNA is strongly mutagenic and can contribute to cell disfunction [22].

The objective of this paper is concerned with the electrochemical study of the interaction of thiophene- $S$ oxide in situ with dsDNA at a charged interface using a thick-film modified glassy carbon electrode. The electrochemistry of the thiophene- $S$-oxide (Scheme 1) was investigated as well as its interaction with dsDNA. The experimental results presented here will give strong evidence that the reduced thiophene- $S$-oxides interact with dsDNA causing damage and that the thiophene- $S$ oxide adduct with dsDNA can still undergo reduction.

\section{Experimental}

\subsection{Reagents}

Thiophene- $S$-oxides were prepared directly from the corresponding thiophenes by oxidation with $m$-CPBA in the presence of $\mathrm{BF}_{3} \cdot \mathrm{Et}_{2} \mathrm{O}$ as a Lewis acid [23]. Typically, the reaction is carried out at low temperature, where the Lewis acid both activates the peracid as well as stabilizes the thiophene- $S$-oxide formed through complexation, thus hindering further oxidation of the product to the more stable thiophene $S, S$-dioxide species.

For electrochemical studies with 3,4-dibenzyl-2,5dimethylthiophene- $S$-oxide (2) (Scheme 2), two procedures were followed. On the one hand, solutions of $1 \times 10^{-3}$ M 3,4-dibenzyl-2,5-dimethylthiophene- $S$ oxide were prepared in aqueous buffer plus $50 \% \mathrm{EtOH}$
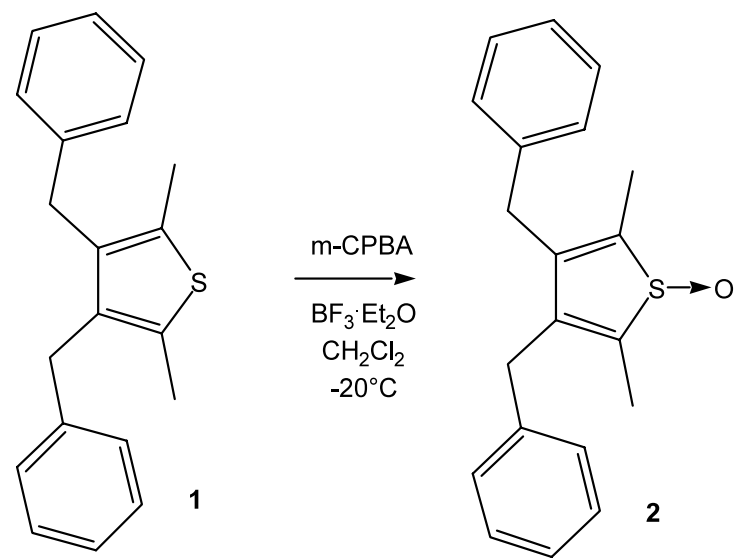

Scheme 1. Chemical structure and preparation of 3,4-dibenzyl-2,5dimethylthiophene- $S$-oxide (2). 


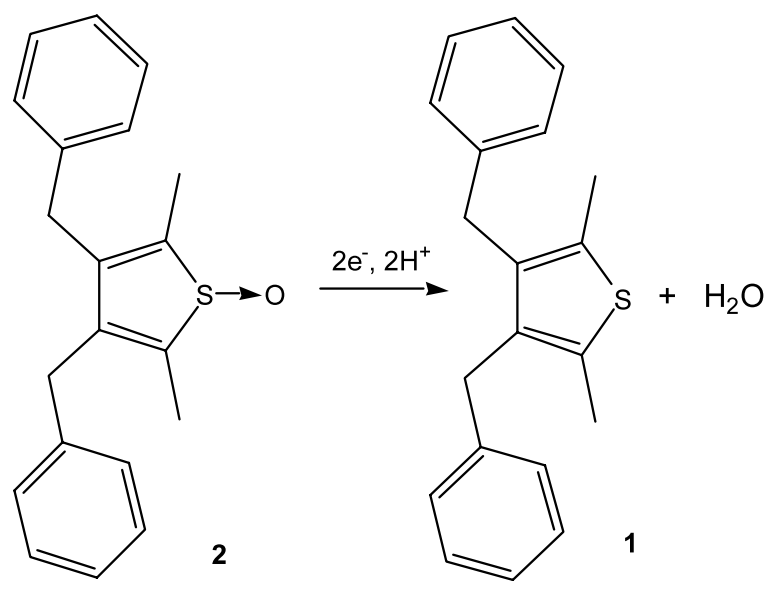

Scheme 2. Reduction mechanism for 3,4-dibenzyl-2,5-dimethylthiophene- $S$-oxide (2).

(v/v). On the other hand, for solid-state electrochemistry [24] in electrolyte solutions with different $\mathrm{pH}$ (Table 1), the glassy carbon electrode surface was mechanically pressed onto the solid compound before the electrode was immersed in the electrolyte. To study the interaction with dsDNA, $35 \mathrm{mg}$ of the compound were mixed with a dsDNA solution, $35 \mathrm{mg} \mathrm{ml}^{-1}$ in $\mathrm{pH} 7.4$ phosphate buffer, which was placed on the glassy carbon electrode surface and dried for $24 \mathrm{~h}$.

Solutions of $0.2 \mathrm{M}$ ionic strength were used in all experiments (Table 1) and were prepared using analytical grade reagents and purified water from a Millipore Milli-Q system (conductivity $<0.1 \mu \mathrm{S} \mathrm{cm}{ }^{-1}$ ).

Calf Thymus DNA (Sodium salt, Type I) was obtained from Sigma Chemical Co. The DNA-modified electrode was prepared by covering a glassy carbon electrode with $80 \mu \mathrm{l}$ of DNA solution (35 mg of DNA dissolved in $1 \mathrm{ml}$ of $\mathrm{pH} 4.5,0.2 \mathrm{M}$ acetate buffer) and leaving the electrode to dry for $24 \mathrm{~h} \mathrm{[16].}$

\subsection{Apparatus}

The $\mathrm{pH}$ measurements were carried out with a Crison $2001 \mathrm{pH}$-meter with a combined glass electrode. All experiments were done at room temperature.

Differential pulse voltammograms were recorded using an Autolab PGSTAT 10 running with GPES

Table 1

Supporting electrolytes, $0.2 \mathrm{M}$ ionic strength

\begin{tabular}{rl}
\hline $\mathrm{pH}$ & Composition \\
\hline 1.20 & $\mathrm{HCl}+\mathrm{KCl}$ \\
4.32 & $\mathrm{HacO}+\mathrm{NaAcO}$ \\
7.40 & $\mathrm{NaH}_{2} \mathrm{PO}_{4}+\mathrm{Na}_{2} \mathrm{HPO}_{4}$ \\
10.20 & $\mathrm{NaOH}+\mathrm{Na}_{2} \mathrm{~B}_{2} \mathrm{O}_{7} \cdot 10 \mathrm{H}_{2} \mathrm{O}$ \\
11.50 & $\mathrm{NaOH}+\mathrm{Na}_{2} \mathrm{HPO}_{4}$ \\
12.00 & $\mathrm{NaOH}+\mathrm{KCl}$ \\
13.00 & $\mathrm{NaOH}+\mathrm{KCl}$ \\
\hline
\end{tabular}

version 4.9 software (Eco-Chemie, Utrecht, The Netherlands). The differential pulse voltammetry conditions used were: pulse amplitude $50 \mathrm{mV}$, pulse width $70 \mathrm{~ms}$ and scan rate $5 \mathrm{mV} \mathrm{s}^{-1}$. The working electrode (WE) was glassy carbon (GCE) $(d=6 \mathrm{~mm})$, the counter electrode was a $\mathrm{Pt}$ wire, and the reference electrode was $\mathrm{Ag}|\mathrm{AgCl}| 3 \mathrm{M} \mathrm{KCl}$, all contained in a onecompartment mini-electrochemical cell with a volumetric capacity of $200 \mu \mathrm{l}$ (Fig. 1), or in a $15 \mathrm{ml}$ electrochemical cell. Cyclic voltammetry scan rates were 50 and $100 \mathrm{mV} \mathrm{s}^{-1}$. The glassy carbon WE was cleaned with diamond spray $(25,6$ and $3 \mu \mathrm{m})$. The differential pulse voltammetry conditions used were: pulse amplitude $50 \mathrm{mV}$, pulse width $70 \mathrm{~ms}$ and scan rate $5 \mathrm{mV} \mathrm{s}^{-1}$. Square wave voltammetry conditions used were: frequency $75 \mathrm{~Hz}$, potential increment $2 \mathrm{mV}$, and effective scan rate $150 \mathrm{mV} \mathrm{s}^{-1}$. Some experiments were carried out under $\mathrm{N}_{2}$ and in order to remove dissolved oxygen, nitrogen was passed through the solution for 30 $\min$.

\section{Results and discussion}

\subsection{Electrochemistry of 3,4-dibenzyl-2,5- dimethylthiophene-S-oxide in a mixed solvent}

The electrochemical study of the oxidation and reduction of 3,4-dibenzyl-2,5-dimethylthiophene- $S$ oxide was performed at different $\mathrm{pH}$ values in a mixed solvent of aqueous buffer plus $50 \%$ ethanol (v/v). The high percentage of ethanol was necessary because of the compound's very low solubility in water. A one-compartment mini-electrochemical cell with a volumetric capacity of $200 \mu \mathrm{l}$ was used (Fig. 1).

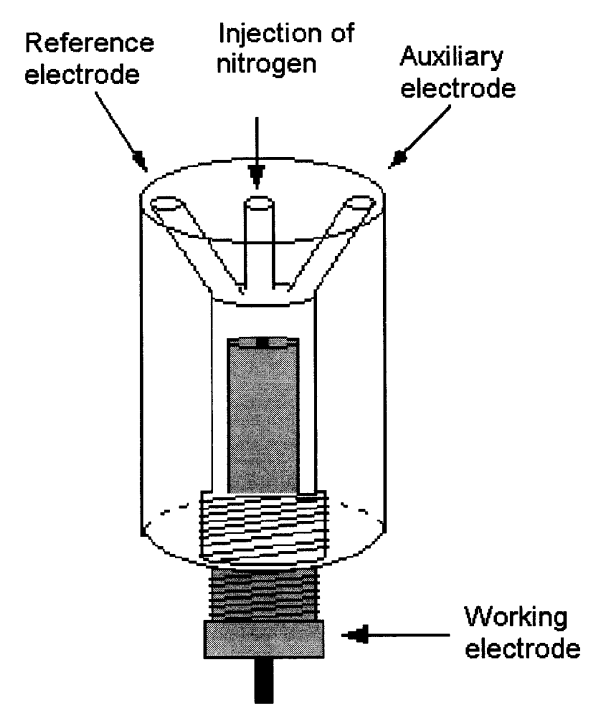

Fig. 1. Schematic representation of the electrochemical microcell. 


\subsubsection{Oxidation}

The electrochemical oxidation of 3,4-dibenzyl-2,5dimethylthiophene- $S$-oxide in aqueous media occurs at a very high positive oxidation potential, $+1.2 \mathrm{~V}$, and only in acid media, pH 1.20 (Fig. 2). At higher $\mathrm{pH}$ values no peak was observed, although the potential range of the supporting electrolyte increased with $\mathrm{pH}$. The electrochemical oxidation of thiophene- $S$-oxides is not readily understood and varies with the substituents both in electrochemical potential as well as in the reaction pathway. Thus far, the only clearly identified oxidation process of a thiophene- $S$-oxide is that of 2,3,4,5-tetraphenylthiophene- $S$-oxide, where the oxidized thia-moiety is extruded and cis-dibenzoylstilbene is formed [25]. It is known that in benzyl substituted and in methyl substituted thiophene- $S$-oxides one of the olefinic moities can isomerize to an exocyclic position under acidic positions [26], effectively forming an $\alpha, \beta$ unsaturated sulfoxide, which can undergo a Michael reaction, e.g. with a heteronucleophile such as ethanol, but which itself can also be oxidized.

\subsubsection{Reduction}

The electrochemical reduction of 3,4-dibenzyl-2,5dimethylthiophene- $S$-oxide occurs at a very high negative reduction potential, and in ethanol only in neutral, $\mathrm{pH} 6.9$ or alkaline media, $\mathrm{pH}>9$, and showed very little variation of the reduction potential with $\mathrm{pH}(19.5 \mathrm{mV}$ per unit of $\mathrm{pH}$ ).

The peak height increased with $\mathrm{pH}$ and a very good definition was obtained for the peak at $-1.4 \mathrm{~V}$ for $\mathrm{pH}$ 12.9 (Fig. 3). The effect of the presence of $\mathrm{O}_{2}$ (supporting electrolyte saturated with $\mathrm{O}_{2}$ ) and absence (supporting electrolyte saturated with $\mathrm{N}_{2}$ ) on the voltammetric behaviour of 3,4-dibenzyl-2,5-dimethylthiophene- $S$-oxide was also investigated. The reduction of 3,4-dibenzyl-

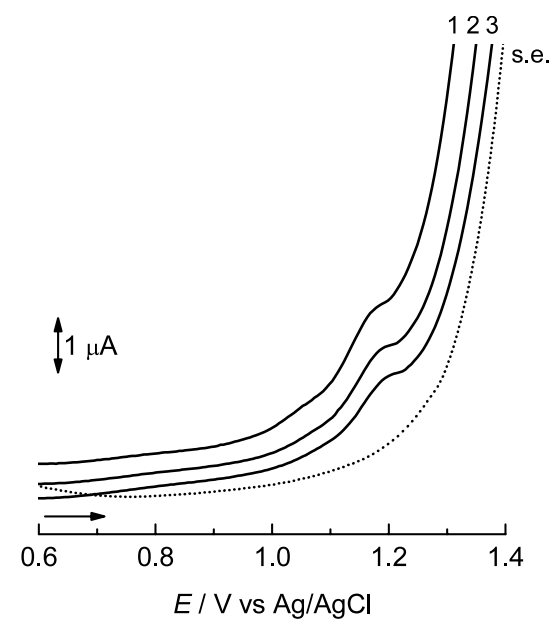

Fig. 2. Successive differential pulse voltammograms for oxidation of $1 \times 10^{-3} \mathrm{M}$ 3,4-dibenzyl-2,5-dimethylthiophene- $S$-oxide (2) $(\mathrm{pH} 1.20)$ plus $50 \%$ ethanol $(\mathrm{v} / \mathrm{v})$. Scan rate $5 \mathrm{mV} \mathrm{s}^{-1}$, amplitude $50 \mathrm{mV}$. s.e.: supporting electrolyte.

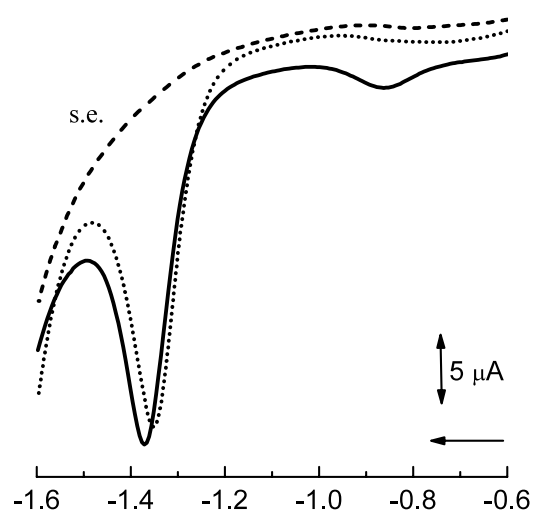

(a)

$E / \mathrm{V}$ vs $\mathrm{Ag} / \mathrm{AgCl}$

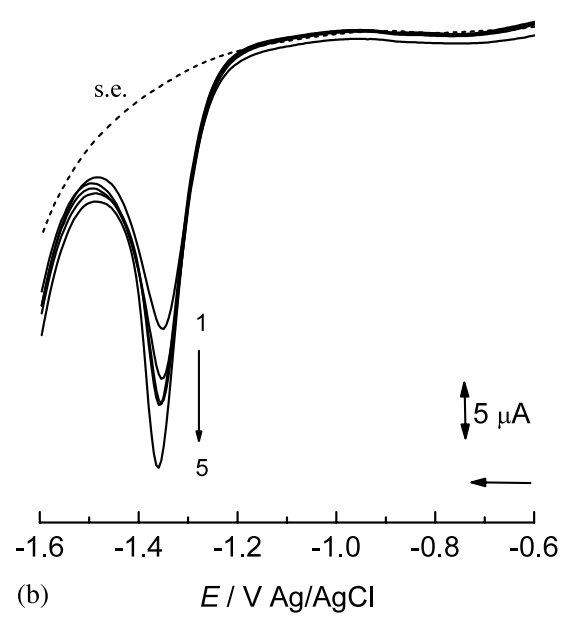

Fig. 3. Differential pulse voltammograms for reduction of $1 \times 10^{-3} \mathrm{M}$ 3,4-dibenzyl-2,5-dimethylthiophene- $S$-oxide (2) (pH 12.85) plus $50 \%$ ethanol (v/v): (a) with (-) and without $(\cdots) \mathrm{O}_{2}$ in the solution; (b) five successive voltammograms. Scan rate $5 \mathrm{mV} \mathrm{s}^{-1}$, amplitude $50 \mathrm{mV}$. s.e.: supporting electrolyte.

2,5-dimethylthiophene- $S$-oxide in a saturated $\mathrm{O}_{2}$ solution did not show appreciable differences (Fig. 3(a)), which means that no interaction of oxygen occurs in the electrochemical reduction mechanism. The oxygen reduction peak is clearly identified at -0.8 V. Five successive scans showed a continuous increase in the reduction peak current possibly due to multilayer formation and polymerization on the electrode surface. Again, this reaction may proceed via isomerisation of one of the double bonds of the thiophene- $S$-oxide into one of the methyl groups, this time under strongly basic conditions, to form a vinyl sulfoxide with the vinyl group being exocyclic. The reason that the 3,4-dibenzyl2,5-dimethylthiophene- $S$-oxide shows different behaviour in ethanol+water than in acetonitrile under more acidic conditions, where in the presence of benzoic acid the molecule can be reduced cleanly to the corresponding thiophene at lower reduction potential [2], is thought to stem from the effective competition of 
both ethanol and water for protons, which under the conditions used here may almost completely suppress protonation of the thiophene- $S$-oxide, necessary for the second mechanism of reduction at lower potential.

Cyclic- and square wave voltammetry of 3,4-dibenzyl2,5-dimethylthiophene-S-oxide in pH 12.9 (Figs. 4 and 5) shows that the electron transfer process is totally irreversible. In cyclic voltammetry, the peak potential is shifted to higher potentials on increasing the scan rate. The square wave voltammograms show a peak for the total current equal to the peak for the forward current, and there is no backward current peak.

\subsection{Solid state electrochemistry of 3,4-dibenzyl-2,5- dimethylthiophene-S-oxide}

Due to the inherently poor solubility of 3,4-dibenzyl2,5-dimethylthiophene- $S$-oxide in the mixed solvent (see Section 3.1) the electrochemistry of this compound was also performed with the solid compound attached by mechanical pressing the glassy carbon electrode surface on the powder in a Petri dish. The compound formed a thick solid film on the glassy carbon surface that was insoluble in the aqueous supporting electrolyte where all voltammograms were recorded. A one-compartment electrochemical cell with a volumetric capacity of 15 ml was used.

The electrochemical reduction of the film of 3,4dibenzyl-2,5-dimethylthiophene- $S$-oxide again occurs at very negative reduction potentials (Fig. 6). Cyclic voltammetry shows an irreversible electron transfer mechanism for the whole $\mathrm{pH}$ range. Differential pulse voltammetry showed the occurrence of other reduction processes at less negative potentials (Fig. 7). All experiments were carried out after passing $\mathrm{N}_{2}$ through the solution for $30 \mathrm{~min}$, so there was no oxygen present in the solution. The occurrence of two peaks at $\mathrm{pH} 11.5$,

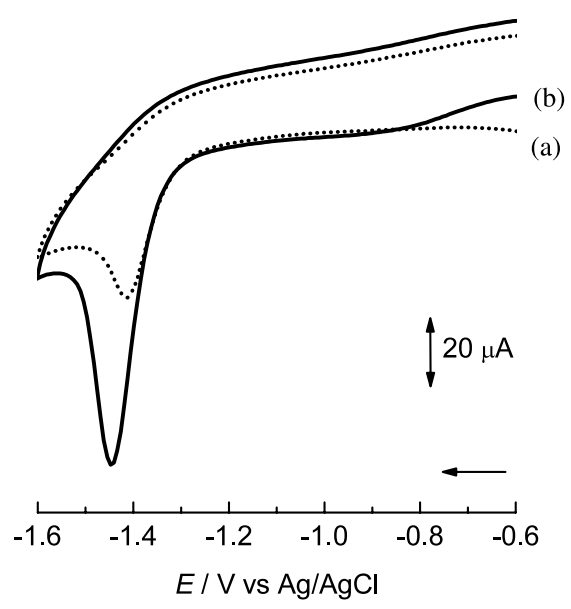

Fig. 4. Cyclic voltammogram for reduction of $1 \times 10^{-3}$ M 3,4dibenzyl-2,5-dimethylthiophene- $S$-oxide (2) ( $\mathrm{pH}$ 12.85) plus $50 \%$ ethanol (v/v). Scan rate: (a) 50; and (b) $100 \mathrm{mV} \mathrm{s}^{-1}$.

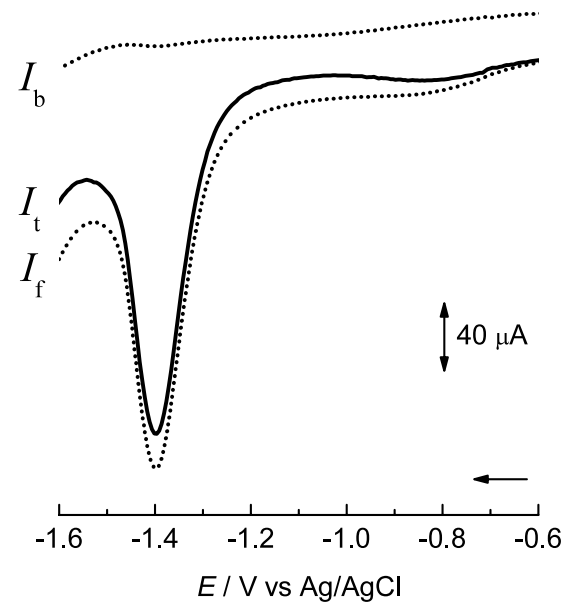

Fig. 5. Square wave voltammogram for reduction of $1 \times 10^{-3}$ M 3,4dibenzyl-2,5-dimethylthiophene-S-oxide (2) (pH 12.85) plus $50 \%$ ethanol (v/v): (1) $I_{\mathrm{t}}$, total current; (2) $I_{\mathrm{f}}$, forward current; (3) $I_{\mathrm{b}}$, backward current. Frequency $50 \mathrm{~Hz}$, amplitude $70 \mathrm{mV}$.

with a separation of $20 \mathrm{mV}$, could be due to different orientations, parallel or perpendicular, of the molecules on the electrode surface and the influence of a different supporting electrolyte. The variation in the reduction potentials with $\mathrm{pH}$ of $45 \mathrm{mV}$ per unit of $\mathrm{pH}$ (Fig. 8) denotes a one electron reduction mechanism with possible formation of dimers up until $\mathrm{pH}$ 10. Dimer formation may proceed via an initial base catalysed isomerisation of one of the double bonds in the heterocyclic ring system of the thiophene- $S$-oxide to an exocyclic position. Isomerisation in thiophene- $S$ oxides has already been noted by us and these dimers have been isolated in other reactions [26]. Above $\mathrm{pH} 10$ the reduction potential is not dependent on the $\mathrm{pH}$ of the solution.

\subsection{Thiophene-S-oxide interaction with dsDNA}

In the potential range available in aqueous solution $(-1.4$ to $+1.4 \mathrm{~V})$ no interaction was detected between 3,4-dibenzyl-2,5-dimethylthiophene-S-oxide and dsDNA, when both are in solution. It is necessary to note that the mixed solvent was $50 \%$ ethanol and that ethanol precipitates DNA, but that it was necessary to use this percentage of ethanol to dissolve the compound.

The interaction of 3,4-dibenzyl-2,5-dimethylthiophene- $S$-oxide with dsDNA, when deposited on the electrode itself, is clearly demonstrated in Figs. 9 and 10. To study the interaction with dsDNA, the glassy carbon electrode was modified with a 1:1 (w/w) solution prepared according to Section 2. The electrode was incubated with the thiophene- $S$-oxide and dsDNA and the deposit was dried on the glassy carbon electrode surface in the $24 \mathrm{~h}$ before the electrochemical measurements were obtained in a sequence of steps which took place in $\mathrm{pH} 7.4$ phosphate buffer electrolyte. 

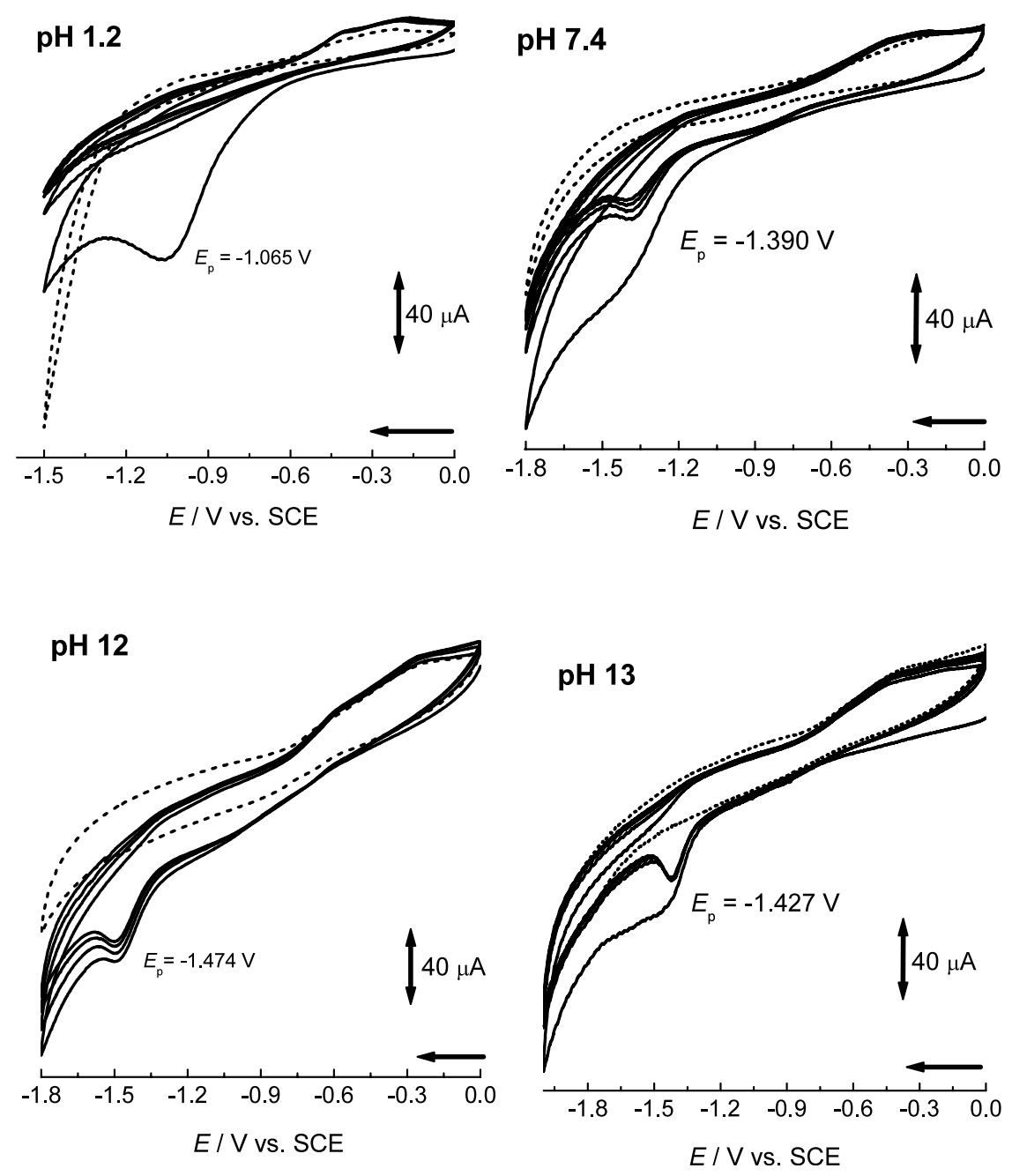

Fig. 6. Successive cyclic voltammograms of a solid film of 3,4-dibenzyl-2,5-dimethylthiophene-S-oxide (2) on glassy carbon, for different pH supporting electrolytes, $\mathrm{N}_{2}$ atmosphere, scan rate $100 \mathrm{mV} \mathrm{s}^{-1}$. (---) supporting electrolyte.

After immersing the glassy carbon electrode, modified by a thick film of 3,4-dibenzyl-2,5-dimethylthiophene- $S$ oxide with dsDNA, in the electrolyte, the first step was to perform three consecutive differential pulse scans in the positive direction 0 to $+1.4 \mathrm{~V}$ versus SCE (Fig. 10, dashed curve) that did not show any peaks, meaning that even after $24 \mathrm{~h}$ incubation the 3,4-dibenzyl-2,5dimethylthiophene- $S$-oxide did not cause any damage to dsDNA.

Immediately afterwards, three consecutive differential pulse scans in the negative direction 0 to $-1.6 \mathrm{~V}$ versus SCE were applied to the same electrode (Fig. 9, dotted curve), and a shoulder appeared corresponding to reduction of the 3,4-dibenzyl-2,5-dimethylthiophene- $S$ oxide.

The next step was the application to the electrode of a potential of $-1.6 \mathrm{~V}$ for $120 \mathrm{~s}$. The result of this was followed first by scanning in the positive direction from 0 to $+1.4 \mathrm{~V}$ (Fig. 10, Curve 1). This differential pulse voltammogram at $\mathrm{pH} 7.4$ shows clearly the appearance of two peaks corresponding to the oxidation of the
DNA purine bases [11,14-17], guanine $(\mathrm{G})$ at $E_{\mathrm{p}}=$ $+0.73 \mathrm{~V}$ and adenosine (A) $E_{\mathrm{p}}=+1.23 \mathrm{~V}$. The electrochemical oxidation at a bare GCE of guanine $(\mathrm{G})$, guanosine (Guo), adenine (A), and dsDNA involves two electrons and two protons which means that the oxidation potential values vary with the supporting electrolyte $\mathrm{pH}$ in a $\mathrm{pH}$ dependent mechanism [11,1417]. The differential pulse scan in the negative direction from 0 to $-1.6 \mathrm{~V}$ showed an increase of the reduction peak of 3,4-dibenzyl-2,5-dimethylthiophene- $S$-oxide (Fig. 9, Curve 1).

Repetition of this procedure, i.e. application to the electrode of a potential of $-1.6 \mathrm{~V}$ for $120 \mathrm{~s}$, and following the result by scanning in the positive direction from 0 to $+1.4 \mathrm{~V}$ (Fig. 10, Curve 2) showed the appearance of a new peak corresponding to 8-oxoguanine (8-oxoG) $[16,27]$ at $E_{\mathrm{p}}=+0.40 \mathrm{~V}$, and the decrease of the guanine and adenosine peaks, the latter becoming a small shoulder. The scan in the negative direction shows an increase in the reduction peak of 3,4-dibenzyl2,5-dimethylthiophene- $S$-oxide (Fig. 9, Curve 2). 

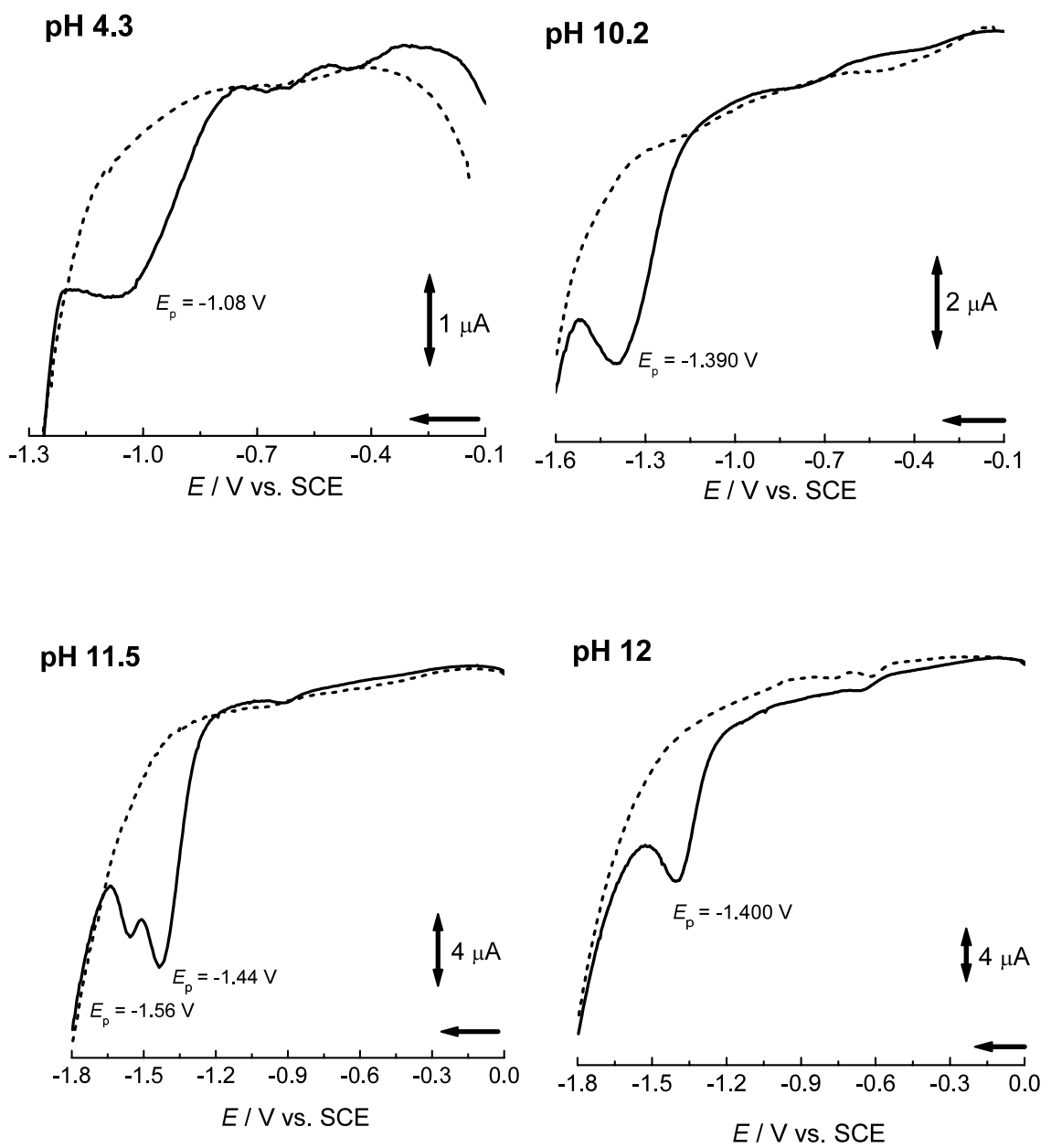

Fig. 7. Differential pulse voltammograms of a solid film of 3,4-dibenzyl-2,5-dimethylthiophene- $S$-oxide (2) on glassy carbon, for different $\mathrm{pH}$ supporting electrolytes, $\mathrm{N}_{2}$ atmosphere, scan rate $5 \mathrm{mV} \mathrm{s}^{-1}$. (---) supporting electrolyte.

The procedure was repeated again and the result of scanning in the positive direction from 0 to $+1.4 \mathrm{~V}$ (Fig. 10, Curve 3) showed the increase of the peak for

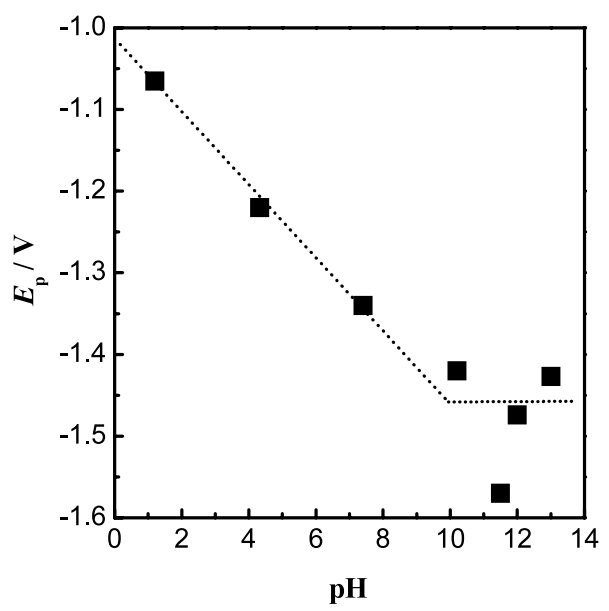

Fig. 8. Plot of $E_{\mathrm{p}}$ vs. $\mathrm{pH}$ from differential pulse voltammograms of a solid film of 3,4-dibenzyl-2,5-dimethylthiophene- $S$-oxide on glassy carbon, for different $\mathrm{pH}$ supporting electrolytes, $\mathrm{N}_{2}$ atmosphere, scan rate $5 \mathrm{mV} \mathrm{s}^{-1}$. 8-oxoguanine, and the complete disappearance of the guanine and adenosine peaks. The scan in the negative direction continues showing an increase in the reduction peak of 3,4-dibenzyl-2,5-dimethylthiophene- $S$-oxide (Fig. 9, Curve 3).

The complete experiment described was done five times, each time with a newly prepared glassy carbon modified electrode and the results obtained were always the same.

The reduction of 3,4-dibenzyl-2,5-dimethylthiophene$S$-oxide at $-1.6 \mathrm{~V}$ clearly conditions the interaction with dsDNA. The possible in situ formation of reactive radicals in the mixture on the electrode surface in close contact with dsDNA is responsible for the damage to dsDNA always detected after application of $-1.6 \mathrm{~V}$. Since experiments were carried out in buffer, the peaks recorded for reduction or oxidation can be attributed only to the molecules in the thick layer on the surface of the glassy carbon. The damage to dsDNA was detected electrochemically in Curve 1 (Fig. 10) by the appearance of the guanine and adenosine peaks after distortion of the dsDNA and possible strand break. These peaks 


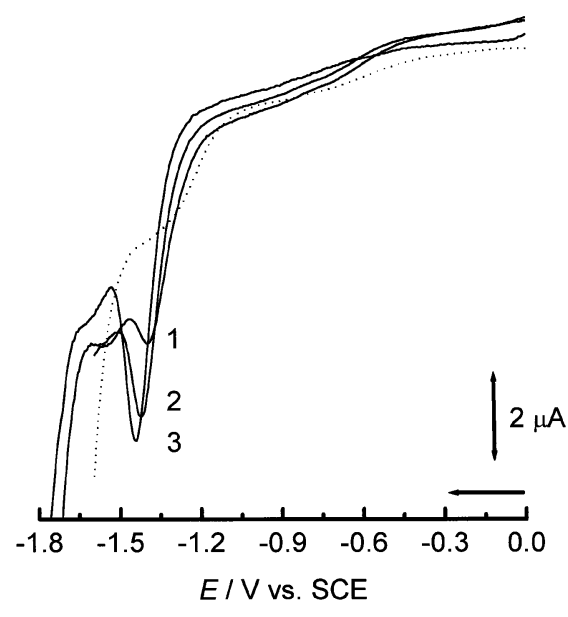

Fig. 9. Differential pulse voltammograms of a glassy carbon electrode modified by a film of a mixture of dsDNA and 3,4-dibenzyl-2,5dimethylthiophene- $S$-oxide (2), after scanning between 0 and $+1.4 \mathrm{~V}$, in $\mathrm{pH} 7.4$ phosphate buffer: $(\cdots)$ before and $(-)$ voltammograms $(1$, 2 and 3) after the application of $-1.6 \mathrm{~V}$ during $120 \mathrm{~s}$ followed by scanning between 0 and $+1.4 \mathrm{~V}$. Scan rate $5 \mathrm{mV} \mathrm{s}^{-1}$.

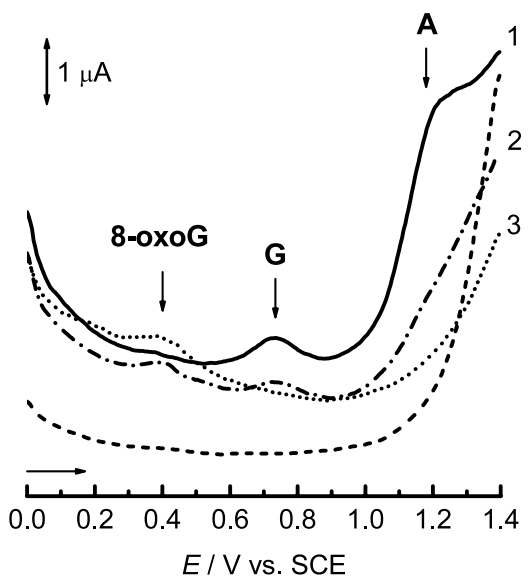

Fig. 10. Successive differential pulse voltammograms of a glassy carbon electrode modified by a film of a mixture of dsDNA and 3,4dibenzyl-2,5-dimethylthiophene-S-oxide (2), in $\mathrm{pH} 7.4$ phosphate buffer: (---) first scan between 0 and $+1.4 \mathrm{~V},(1,2$ and 3$)$ scans after the application of $-1.6 \mathrm{~V}$ for $120 \mathrm{~s}$. Scan rate $5 \mathrm{mV} \mathrm{s}^{-1}$.

subsequently disappeared because both guanine and adenosine reaching the electrode were oxidised, and the peak for mutagenic 8-oxoguanine (Curve 2), a product of the oxidation of guanine, started appearing and increased (Curve 3). The mechanism of damage of dsDNA by the thiophene- $S$-oxide could be explained by intercalation or by electrostatic interaction.

The formation of an adduct between the dsDNA and the 3,4-dibenzyl-2,5-dimethylthiophene- $S$-oxide is responsible for the shift of $\sim 100 \mathrm{mV}$ to more negative potentials of the reduction peak of the thiophene- $S$ oxide and the increase in current (Fig. 9), possibly caused by reorganization of the compound in the mixture, is electrochemical evidence of interaction with dsDNA, which is also confirmed by the results in Fig. 10 that show electrochemical oxidation of the DNA bases.

\section{Conclusions}

The electrochemical study of 3,4-dibenzyl-2,5-thiophene- $S$-oxide was performed for different $\mathrm{pH}$ values, in a mixed solvent and by solid state voltammetry. The in situ electrochemical detection of dsDNA damage caused by the reduced thiophene- $S$-oxide was possible using a glassy carbon electrode modified with a thiophene- $S$ oxide/dsDNA mixture. The results indicate that after interaction with dsDNA the adduct compound formed can still undergo reduction. The potential use of a compound/dsDNA film-modified glassy carbon electrode for understanding dsDNA interaction with molecules insoluble in water, as in this case, should be noted.

\section{Acknowledgements}

Financial support from Fundação para a Ciência e Tecnologia (FCT), POCTI (co-financed by the European Community Fund FEDER), ICEMS (Research Unit 103) and European Projects QLK3-2000-01311 and HPRN-CT-2002-00186 are gratefully acknowledged.

\section{References}

[1] Y.-Q. Li, M. Matsuda, T. Thiemann, T. Sawada, S. Mataka, M. Tashiro, Synlett (1996) 461.

[2] T. Thiemann, D. Ohira, K. Arima, T. Sawada, S. Mataka, F. Marken, R.G. Compton, S.D. Bull, S.G. Davies, J. Phys. Org. Chem. 13 (2000) 648.

[3] M.E. Randazzo, L. Toppare, J.E. Fernandez, Macromolecules 27 (1994) 5102.

[4] A. Bongini, G. Barbarella, M. Zambianchi, C. Arbizzani, M. Mastragostino, J. Chem. Soc., Chem. Commun. (2000) 439.

[5] P. Pouzet, I. Erdelmeier, D. Ginderow, J.-P. Mornon, P. Dansette, D. Mansuy, J. Chem. Soc., Chem. Commun. (1995) 473.

[6] T. Thiemann in a collaboration with the National Cancer Institute, Bethesda, Maryland, USA, as part of its Developmental Therapeutics Program.

[7] P. Pouzet, I. Erdelmeier, P.M. Dansette, D. Mansuy, Tetrahedron 54 (1998) 14811 (and references cited therein).

[8] P.M. Dansette, Do Cao Thang, H. El Amri, D. Mansuy, Biochem. Biophys. Res. Commun. 186 (1992) 1624.

[9] A. Treiber, P.M. Dansette, H. El Amri, J.-P. Girault, D. Ginderow, J.-P. Mornon, D. Mansuy, J. Am. Chem. Soc. 119 (1997) 1565.

[10] W. Saenger, Principles of Nucleic Acid Structure, SpringerVerlag, New York, 1984.

[11] A.M. Oliveira-Brett, S.H.P. Serrano, J.A.P. Piedade, in: R.G. Compton, G. Hancock (Eds.), Comprehensive Chemical Kinetics, chap. 3, Elsevier, Amsterdam, 37, 1999, 91-119. 
[12] E. Palecek, M. Fojta, M. Tomschik, J. Wang, Biosens. Bioelectron. 13 (1998) 621.

[13] M. Mascini, I. Palchetti, G. Marrazza, Fresenius J. Anal. Chem 369 (2001) 15.

[14] A.M. Oliveira Brett, F.-M. Matysik, J. Electroanal. Chem. 429 (1997) 95.

[15] A.M. Oliveira Brett, F.-M. Matysik, Bioelectrochem. Bioenerg. 42 (1997) 111.

[16] G.M. Blackburn, M.J. Gair, Nucleic Acids in Chemistry and Biology, Oxford University Press, Oxford, UK, 1996.

[17] A.M. Oliveira-Brett, M. Vivan, I.R. Fernandes, J.A.P. Piedade, Talanta 56 (2002) 959.

[18] C.M.A. Brett, A.M. Oliveira Brett, S.H.P. Serrano, J. Electroanal. Chem. 366 (1994) 225.

[19] E.L. Kostoryz, D.M. Yourtee, Mutat. Res. 490 (2001) 131.
[20] K. Kiyomiya, S. Matsuo, M. Kuruebe, Cancer Chemother. Pharmacol. 47 (2001) 1:51-56.

[21] I. Muller, A. Jenner, G. Bruchelt, D. Niethammer, B. Halliwell, Biochem. Biophys. Res. Commun. 230 (1997) 254.

[22] S.S. David, S.D. Williams, Chem. Rev. 98 (1998) 1221.

[23] Y.Q. Li, T. Thiemann, T. Sawada, S. Mataka, M. Tashiro, J. Org. Chem. 62 (1997) 7926.

[24] P.J. Kulesza, J.A. Cox, Electroanalysis 10 (1998) 73

[25] J. Iniesta Valcarel, D.J. Walton, H. Fujii, T. Thiemann, Y. Tanaka, S. Mataka, T.J. Mason, J.P. Lorimer, New J. Chem., submitted for publication.

[26] T. Thiemann, Kyushu Daigaku Chuo Bunseki Senta Hokoku 18 (2000) 1-7; Chem. Abstr. 134 (2001) 326045j.

[27] A.M. Oliveira Brett, J.A.P. Piedade, S.H.P. Serrano, Electroanalysis 12 (2000) 969. 